\title{
Study and overview on WBAN under IEEE 802.15.6
}

\author{
John Harrison Kurunathan \\ Department of Electrical Engineering, Faculty of Engineering University of Porto, Porto, \\ Portugal (hhkur@isep.ipp.pt)
}

\begin{abstract}
WBAN (wireless body area networks) is an upcoming technology which stands to be a base for wearable and implantable sensors. The IEEE 802.15.6 formulates the physical and medium access for body area networks. The Body area networks can be implemented in several applications like health monitoring, ambient living environments and consumer electronics. This paper gives a clear overview about the functions of WBAN. The medium access layers and the physical layers of IEEE 802.15.6 are deeply examined and studied in this work. The access mechanisms of the protocol are explained in this paper. A clear literature review has also been stated to know the current state of art of this technology. The future possibilities and area to be explored also has been defined in this work.
\end{abstract}

Subject Headings. Medical Applications, Communication

Author Keywords. IEEE 802.15.6, Wireless body area networks

\section{Introduction}

In the current world population 750 million people are aged above 60, it has been also estimated that by the year 2050 this amount will increase 2 billion. This gives us a reason to look into several health care techniques that can provide quality life to the aged. Recent advancements in electronics have found its era into the development of efficient medical sensors. These sensors are well miniaturized that they can be either worn on a human body or implanted inside the skin. The concept behind these medical sensors is that these sensors detect the data from the body system and send the data to an external server where this recorded data is analyzed and stored for further use. Using a wired interface for this kind of interface may is burdensome as it requires lot of cost involved and also affects the mobility of the patient. Cypher, D et al have discussed the challenges that prevail over a wired system for health care communication (Cypher et al. 2006). A wireless interface will be an effective alternate for this use; these systems will be effective as well as facilitate the mobility of the patient. This will definitely prove to be an effective technique to push the diagnosis of patients and health care systems to a next level. Istepanian's (2004) idea of mHealth can be bought to reality where the patient's condition can be diagnosed and treated by electronic means. Van Dam (2001) gave the idea of wearable sensors and termed body area networks, this idea can be fully exploited by putting use of the current advancements in technologies.

Park (2003) in his work clearly defines what a wearable health care technology should have in it, He brings out the idea of sensors that are capable of recording the impulses from the human body internally or externally, these impulses may vary from a heartbeat, brain signal, sensorimoter signal or an ECG. This device is either planted on the body or within the body; they must have the capability of transmitting the signal recorded by them through a wireless medium. These devices are responsible to provide the signal to a medical personnel, this may vary either continuously or periodically based on the type of signal to be diagnosed. 
Park also suggests the idea of storing this data for a specific amount of time so that the system can analyze and improve the quality based on the patients' readings. Apart from sensors actuators can also introduced in this technology. Some actuators that are commercially available are the diabetes dozer and the pacemaker. They are made to actuate themselves depending on the condition of the patient. In case if the patient suffers from a severe heart attack, variation from a normal heart rate can be detected using an ECG signal that in turn provides the signal to the pacemaker to actuate. User interaction to these technologies is also feasible where a user can check these body parameters like temperature, heart rate, pressure, diabetes level, cholesterol through an external device like a cell phone which can communicate with the sensors in the body. This is the part where wireless body area networks (WBAN) come in. Several Challenges have to be considered when developing a body area network power concern is a very important aspect in the developing technologies, when developing miniature devices that operate inside or the vicinity of the human body the form factor of the power sources that empower these system is extremely small, yet still a very high lifetime of the device has to be planned. These devices being used in health care applications should be handled with much care as a life of a patient may depend on the device. In reference to IEEE standard for safety levels with respect to human exposure to radio frequency electromagnetic fields (IEEE standard for safety levels with respect to human exposure to radio frequency. 1999) the transmit power at every node must be much minimized. The propagation medium may be in lossy layer like an epidermis layer of a skin, there is always interference due to the medium hence they have to be properly attenuated before being given to the receiver. The success of these systems will solely rely on less delay and high reliability of the medical information that is transmitted through the nodes. IEEE 802 established a Task Group called IEEE 802.15.6 for the standardization of WBAN (IEEE P802.15.6/D01. 2010).

The paper is organized into the following IEEE 802.15.6 description, MAC, PHY, state of the art of research in WBAN, future project ideas based on WBAN.

\section{IEEE 802.15.6 Description}

Due to the increasing interests and the necessity of improving health care applications WBAN found its importance and caught the eye of several researchers. IEEE Standards Association formed the IEEE 802.15 Task Group 6 in November 2007. It quotes: "The IEEE 802.15 Task Group 6 (BAN) is developing a communication standard optimized for low power devices and operation on, in or around the human body (but not limited to humans) to serve a variety of applications including medical, consumer electronics/ personal entertainment and other"[IEEE 802.15 WPAN Task Group 6 Body Area Networks. 2011]. WBAN networks require bandwidths that can provide a very high data rate. Implant chip communication operates at the frequency range of $402-405 \mathrm{MHz}$. This frequency range is determined by Medical implant communication services; this frequency of operation is almost same as that of Medical telemetry services. Industrial scientific and medical Band (ISM) provides a very high data rate but suffers from interference issues because of devices of IEEE 802.1 and 802.11.4 operate in the same band.

The IEEE 802.15.6 standard defines three physical Such as the Narrowband (NB), Ultra wideband (UWB), and Human Body Communications (HBC) layers. Based on the type of application, the network is to be implemented the PHY layer can be varied accordingly. It has a sophisticated MAC layer that facilitates the control operation of the entire system. The Nodes that communicate are organized into logical sets controlled by a collective hub as 
shown in figure 1. The topology is varied on base on hops in a one-hop star BAN, the exchange of frames occur directly only between nodes and the hub of the BAN, whereas in a two-hop extended star BAN, the hub and a node may exchange frames via a relay capable node.

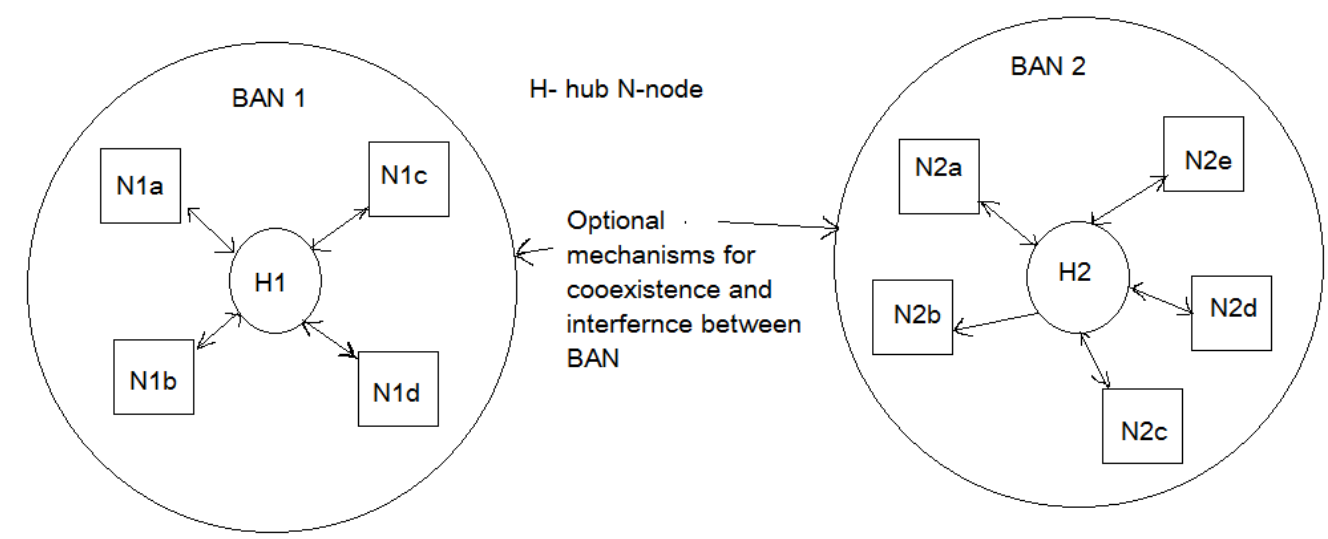

Figure 1: BAN network star topology

For time referenced resource allocations, the hub of each BAN topology divides the time axis into a set of superframes. The superframes are restricted by beacon periods. The beacon period have same length along the entire time axis. The hub or the coordinator of the system have the entire control and also can select the boundaries of beacon periods as well as shift the offsets of the beacon period (S. Saleem et al. 2011). Security levels are very much sophisticated in this protocol. A three layer security is provided in this protocol they are unsecured communication, authentication only mode and authentication and encryption mode.

\section{PHY Layer of IEEE 802.15.6}

The narrow band physical layer has certain function to carry on such as the activation and the deactivation of the nodes, data transmission and reception along the channel. As this band is responsible for the transmission of the signals this also does the clear channel assessment within the current channel that is transmitting the signal. The Physical Protocol Data Unit (PPDU) frame of Narrow Band of PHY IEEE 802.15.6 has a Physical Layer Convergence Procedure (PLCP) preamble, a PLCP header, and a PHY Service Data Unit (PSDU). The physical protocol data unit is shown in figure 2.

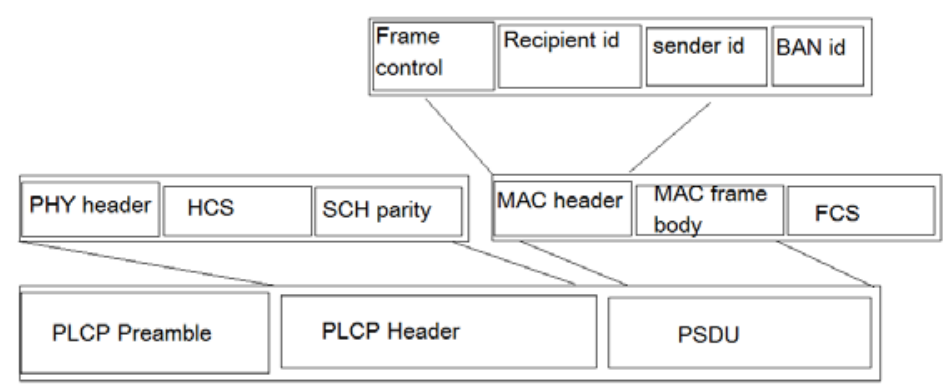

Figure 2: PPDU of Narrow band PHY

Physical Layer Convergence Procedure (PLCP) preamble takes responsibility of timing synchronization in the receiver end. A carrier recovery system estimates and compensates for frequency and phase differences between a received carrier wave and the receiver's local oscillator. This is done for the purpose of effective demodulation matching the coherent waves of the signal, PLCP preamble does this function. This region of the PHY layer gives the necessary data for decoding operation in the receiver end. PLCP header is transmitted after 
the preamble. The PLCP will read in the PLCP preamble and header of the frame to synchronize the receiver to the data rate of the signal. After sending the header, the transmitter changes the data rate of the transmission to what the header specifies for transmitting the PSDU (S. Ullah et al. 2011). Then comes the MAC header, MAC frame body, Frame Check Sequence (FCS). These components give the function correspondence to the MAC layer. They are transmitter after the physical layer convergence procedure and they can be accessed by the data rates that are available at the operating frequency band. NB PHY uses several shift keying techniques such as Differential Binary Phase-shift Keying (DBPSK), Differential Quadrature Phase-shift Keying (DQPSK), and Differential 8- Phase-shift Keying (D8PSK) modulation techniques and Gaussian minimum shift keying (GMSK) technique. The shift keying techniques vary depending on the frequency of operation.

The Ultra Wide Band PHY layer operates in both higher frequency and lower frequency bands. The band is divided into channels. Each channel is of bandwidth of $499.2 \mathrm{MHz}$, The lower band consists of 3 channels, whereas the higher bandwidth has 8 channels, which can be numbered as 4 to 11 . Channel 2 and channel 7 have central frequencies of $3993.6 \mathrm{MHz}$ and 7987.2 $\mathrm{MHz}$ respectively. These channels are considered to be the mandatory channels and the other channels are kept optional. A device that works on the ultra wide band should support at least one of the mandatory channels. Low implementation complexity is one of the advantages in implementing in the ultra wide band.

\begin{tabular}{|c|c|c|c|c|c|c|}
\hline $\mathrm{Si}$ & $\mathrm{Si}$ & $\mathrm{Si}$ & so & so & PHR & Data \\
\hline \multicolumn{4}{|c|}{ Preamble } & SFD & PHR & PSDU \\
\hline \multicolumn{7}{|c|}{ PHY protocol data Unit PPDU } \\
\hline
\end{tabular}

Figure 3: PDDU of UWB PHY

The UWB PPDU contains a Synchronization Header (SHR), a PHY Header (PHR), and PSDU as shown in figure 3. The SHR contains a preamble and a Start Frame Delimiter (SFD). The Physical header has the information about data rate of the PSDU, length of the payload. A scrambler manipulates the data information before transmission of the data. The PHY header also has the information on the scrambler seeding. Decoding of the PSDU is done with respect to the information given by the physical header. Kasami sequences are binary sequences of length $2 \mathrm{~N}-1$ where $\mathrm{N}$ is an even integer. Kasami sequences have good crosscorrelation values hence they are used in the receiving end. The SHR is made repetitions of Kasami sequences of length 63. The data rates of this band range from $0.5 \mathrm{Mbps}$ up to 10 Mbps with $0.4882 \mathrm{Mbps}$ as the mandatory one.

The human body communications physical layer (HBC- PHY) uses the electric field communication (EFC) technology. This PHY operates at a centered frequency of $21 \mathrm{MHz}$. PLCP Preamble, Start Frame Delimiter (SFD), PLCP Header, and PHY Payload (PSDU) constitutes the entire HBC PHY layer. The PHY Payload comprises of MAC Header, MAC Frame Body, and frame check sequence (FCS). The data to be transmitted is spread in the frequency domain using frequency selective spread codes; this methodology is called as the frequency selective digital transmission (FSDT) scheme. This is done prior to the transmission of data. The center frequency for the transmission is selected by using the specific frequency selective spread code of the data transmitted. The packet structure of HBC PHY is given below. 


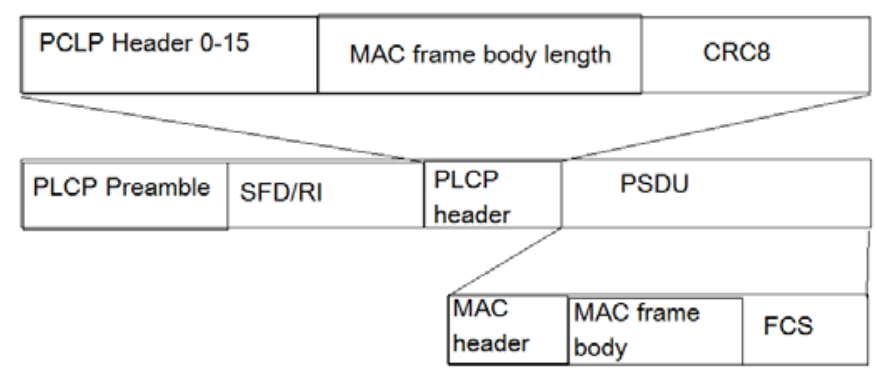

Figure 4: Packet structure of $\mathrm{HBC}$ PHY

\section{MAC Layer of IEEE 802.15.6}

In WBAN the entire channel is divided into superframe structures. The superframe is comprised of network beacons. Every network beacon is of the same size. The central hub is responsible for selecting the boundaries of the beacon period, transmitting a beacon frame at every superframe beacon period. At the conditions of inactive superframes the corresponding beacon transmission time is shifted. This process is done including a beacon Shifting Sequence field in the beacons of inactive superframe sequences. The hub transmits a beacon at every time allocation. When a proper supporting time referenced allocation is not given to the hub, it operates without taking any superframe to account or never transmitting any data. The MAC layer of IEEE 802.15.6 works under three modes of operations, they are beacon mode with beacon period superframe boundaries, non-beacon mode with superframe boundaries, and non-beacon mode without superframe boundaries.

Before having an overview about the various modes common idea about the terms used to describe the mechanisms is given below.

Beacon is a signal that is sent along the first slot of any superframe. They hold the responsibility of initializing the superframe. The beacon identifies the coordinator, manages the network and the power of the transmitting systems and also does the time synchronization of the data. Beacon two frame also called beacon2 is used to indicate the start and the exit of contention access phase (CAP), acknowledgement given by many nodes also called "grouping acknowledgment) and fast adaptation.

Exclusive access phases also called as EAP is used in case of an emergency traffic, they are the access phases which are used when the data to be transmitted is of a high priority than its preceding data to be transmitted. This is of two types EAP1 and EAP2. Random access phase and contention access phase are used for the normal traffic where there are no critical emergency conditions, similar to the EAP; RAP is also of two types RAP1 and RAP2. Type I access phase is used for uplink, downlink and bi-link allocation. It improvises both polled and post allocations outside the given scheduled allocation as well as bilink scheduled allocations. Type I allocation is defined in terms of its time duration and type II is defined in terms of frame count. Type II access phase is mainly used for bilink and delayed bilink allocation intervals. It improvises both polled and post allocations outside the given scheduled allocation as well as bilink scheduled allocations.

Beacon mode with beacon period superframe boundaries: In this mode the hub transmits a beacon frame in every beacon period during the issue of a superframe but remains inactive otherwise. The superframe structure of IEEE 802.15.6 consists of the following phases beacon, Exclusive Access Phase (EAP1, EAP2), Random Access Phase (RAP1, RAP2), Type I/II phase, Exclusive Access and a Contention Access Phase (CAP). (Figure 5)

Non-beacon mode with superframe boundaries: In this mode the hub can have superframe only one in type I or II access phase. The transmission time is relative to the start of current 
superframe, this is given by timed frame T-Poll. T poll is an equivalent to the Poll frame that contain a transmit timestamp for superframe boundary synchronization. The hoop can improvise in terms of post and poll allocation of the time frames. (Figure 6)

Non-beacon mode without superframe boundaries: In this mode there are no superframe boundaries. The hub can provide only unscheduled type II polling access method. (Figure 7)

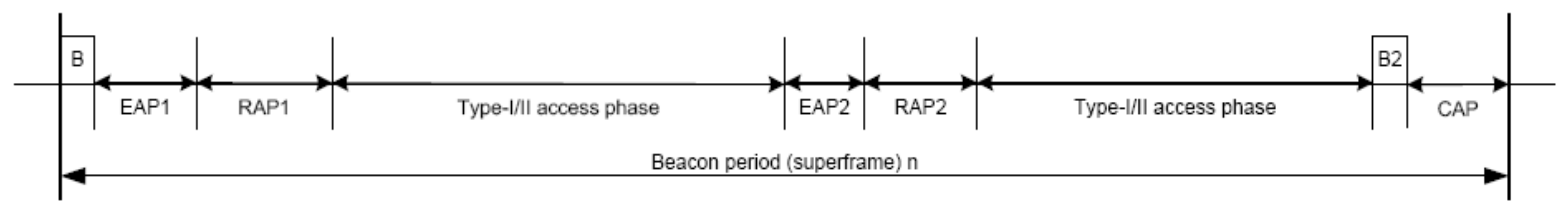

Figure 5: Beacon mode with beacon period superframe boundaries

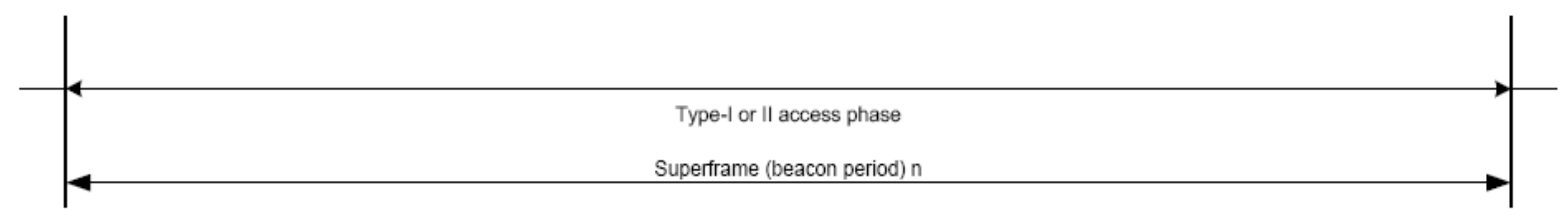

Figure 6: Non-beacon mode with superframe boundaries

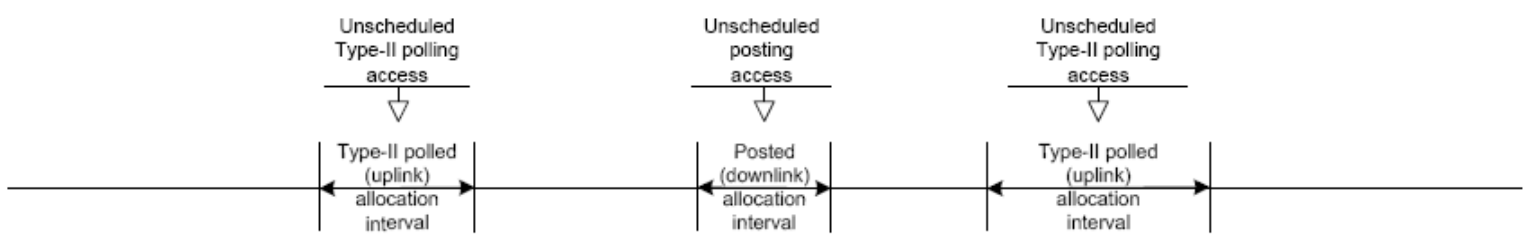

Figure 7: Non-beacon mode without superframe boundaries

\subsection{Access mechanisms}

The allocations in Exclusive Access Phases, Random Access Phases and the Contention Access Phase are more confined and the access methods that are used to get the allocations are CSMA/CA and slotted aloha access. If a hub or a node try to send data types frames in an emergency access phase with a high priority the hub attains allocation right at the start of the phase of EAP without affecting the CSMA/CA or slotted aloha access mechanisms. Whereas if the hub wants to transmit data either in the random access phase or the contention access phase, The allocation is constrained and does not have the pre-emptive privilege of an EAP.

4.1.1 CSMA/CA: This access mechanism uses a back off counter and a contention window to get a new allocation. A node has the privilege to initiate, use, modify, abort or end a contended allocation. In this access mechanism the node initializes its counter to a random integer value between one and a contention window (CW). $\mathrm{CW}$ varies depending on the user priority it varies from CWmax to CWmin. Then the counter decremented constantly till a CSMA slot is equal to pCSMASlotLength. When the counter reaches zero the data is transmitted. In case the counter reaches CWmax (higher priority) the $\mathrm{CW}$ will be doubled and the channel will be busy.

4.1.2 Slotted Aloha access: This access mechanism uses contention probability. A node obtains a new contended allocation in an Aloha slot based on this probability. A node has the similar privileges to that of a CSMA/CA mechanism.

4.1.3 Unscheduled access: In this access mechanism a hub employs unscheduled polling and posting access to send polls or posts at any time across the frame. The active bit of the node 
will be set to 1 and the node will stay active making itself available for grant polled or post allocations which may be even unscheduled.

4.1.4 Improvised access: A hub may employ unscheduled polling and posting access. It has the privileges of a RAP in both polling and post allocations.

\section{State of the Art of WBAN Technologies}

Table 1 has been formulated below indicating the author and their works done in the field of WBAN. The table mainly concentrates on the protocol IEEE 802.15.6. Many of the researches done are mainly application oriented in the field of medicine and wireless networks.

\begin{tabular}{|c|c|c|c|c|}
\hline Author & Idea of approach & Method done & Application & $\begin{array}{l}\text { Mechanism } \\
\text { used/ region }\end{array}$ \\
\hline $\begin{array}{l}\text { Ni An, Peikang } \\
\text { Wang, Chenfu Yi, } \\
\text { Ye Li }\end{array}$ & $\begin{array}{l}\text { analyzed throughput, delay- } \\
\text { time and energy } \\
\text { consumption under the } \\
\text { saturation and in saturation } \\
\text { conditions }\end{array}$ & $\begin{array}{l}\text { built a 3D } \\
\text { Markovian model } \\
\text { and simulated } \\
\text { using op-net }\end{array}$ & $\begin{array}{l}\text { wearable } \\
\text { sensors }\end{array}$ & CSMA \\
\hline $\begin{array}{l}\text { Mohammad } \\
\text { Sanaullah } \\
\text { Chowdhury et al }\end{array}$ & $\begin{array}{l}\text { estimation of saturation } \\
\text { throughput in a } \\
\text { heterogeneous network of } \\
\text { multiple priority }\end{array}$ & $\begin{array}{l}\text { analytical model is } \\
\text { derived and } \\
\text { checked for a } \\
\text { heterogeneous } \\
\text { network }\end{array}$ & $\begin{array}{c}\text { fitness } \\
\text { monitoring }\end{array}$ & $\begin{array}{c}\text { Slotted Aloha } \\
\text { based }\end{array}$ \\
\hline $\begin{array}{l}\text { Riccardo Cavallari, } \\
\text { Chiara Buratti }\end{array}$ & $\begin{array}{c}\text { analyzed the performance of } \\
\text { MAC layer of BAN }\end{array}$ & $\begin{array}{l}\text { analytical model } \\
\text { composed of one } \\
\text { coordinator and } n \\
\text { transmitting nodes } \\
\text { is derived }\end{array}$ & $\begin{array}{l}\text { mechanisms } \\
\text { based on user } \\
\text { priority can be } \\
\text { developed out } \\
\text { keeping this work } \\
\text { as a base }\end{array}$ & CSMA/CA \\
\hline $\begin{array}{l}\text { Antonio M. Ortiz et } \\
\text { al }\end{array}$ & $\begin{array}{l}\text { method formulated for } \\
\text { extended network life time }\end{array}$ & $\begin{array}{l}\text { adaptive Multi hop } \\
\text { tree based routing } \\
\text { has been used and } \\
\text { fuzzy logic is used } \\
\text { for evaluation }\end{array}$ & $\begin{array}{l}\text { health care } \\
\text { application }\end{array}$ & $\begin{array}{l}\text { routing } \\
\text { region }\end{array}$ \\
\hline $\begin{array}{l}\text { Christos Tachtatzis } \\
\text { et al }\end{array}$ & $\begin{array}{l}\text { analyzed the relation } \\
\text { between data frame rate and } \\
\text { device life time. Energy } \\
\text { savings because of block } \\
\text { transfers has been discussed }\end{array}$ & $\begin{array}{c}\text { analyzed the } \\
\text { relation between } \\
\text { data frame rate and } \\
\text { device life time. } \\
\text { Energy savings } \\
\text { because of block } \\
\text { transfers has been } \\
\text { discussed }\end{array}$ & $\begin{array}{l}\text { low power } \\
\text { medical } \\
\text { applications }\end{array}$ & $\begin{array}{l}\text { scheduled access } \\
\text { modes of BAN }\end{array}$ \\
\hline $\begin{array}{l}\text { leake Zegeye } \\
\text { Kahsay et al }\end{array}$ & $\begin{array}{l}\text { user priority scheme has } \\
\text { been discussed }\end{array}$ & $\begin{array}{l}\text { channel model is } \\
\text { simulated using op- } \\
\text { net and it is } \\
\text { compared to that } \\
\text { of the biomedical } \\
\text { measurements }\end{array}$ & $\begin{array}{l}\text { ambient medical } \\
\text { applications }\end{array}$ & $\begin{array}{l}\text { slotted Aloha } \\
\text { based }\end{array}$ \\
\hline $\begin{array}{l}\text { Umar Fiaz Abbasi } \\
\text { et al }\end{array}$ & $\begin{array}{l}\text { compares CM3A to log } \\
\text { normal path and determines } \\
\text { an improvement in energy's } \\
\text { efficiency }\end{array}$ & $\begin{array}{l}\text { the path loss } \\
\text { models by varying } \\
\text { nodes and inter } \\
\text { arrival time have } \\
\text { been simulated }\end{array}$ & $\begin{array}{l}\text { wireless } \\
\text { networks }\end{array}$ & $\begin{array}{l}\text { routing region - } \\
\text { opportunistic } \\
\text { routing }\end{array}$ \\
\hline
\end{tabular}




\begin{tabular}{|c|c|c|c|c|}
\hline Igor Dotlic et al & $\begin{array}{c}\text { develops a method of } \\
\text { synchronization for } \\
\text { synchronization header and } \\
\text { it's impulse radio UWB PHY } \\
\text { with differential phase } \\
\text { modulation }\end{array}$ & $\begin{array}{l}\text { analytical model for } \\
\text { the synchronization } \\
\text { header, numerical } \\
\text { analysis of various } \\
\text { synchronization } \\
\text { sequences }\end{array}$ & $\begin{array}{l}\text { collision } \\
\text { avoidance in a } \\
\text { multi band } \\
\text { scenario }\end{array}$ & UWB PHY \\
\hline $\begin{array}{l}\text { Mariella } \\
\text { Sarestoniemi et al }\end{array}$ & $\begin{array}{l}\text { performance of UWB } \\
\text { receivers on PHY layer has } \\
\text { been deduced }\end{array}$ & $\begin{array}{l}\text { analytical model for } \\
\text { receiver end was } \\
\text { derived and the } \\
\text { performance is } \\
\text { analyzed by } \\
\text { simulations }\end{array}$ & $\begin{array}{l}\text { wearable } \\
\text { sensors }\end{array}$ & UWB PHY \\
\hline Rashwand, S et al & $\begin{array}{l}\text { data frame size, diversity } \\
\text { order, data frame arrival } \\
\text { rate, access impacts of } \\
\text { channel quality, phase } \\
\text { lengths and error rates have } \\
\text { been studied }\end{array}$ & $\begin{array}{l}\text { 3D Markovian } \\
\text { model is simulated } \\
\text { for the MAC model }\end{array}$ & $\begin{array}{l}\text { wearable } \\
\text { sensors }\end{array}$ & CSMA \\
\hline $\begin{array}{l}\text { Byoung Hoon Jung } \\
\text { et al }\end{array}$ & $\begin{array}{l}\text { performance of the IEEE } \\
802.15 .6 \text { WBAN MAC } \\
\text { protocol in terms of } \\
\text { throughput, power } \\
\text { consumption, and energy } \\
\text { efficiency under unsaturated } \\
\text { condition has been } \\
\text { determined }\end{array}$ & $\begin{array}{l}\text { discrete-time } \\
\text { Markov chain } \\
\text { based analytical } \\
\text { model has been } \\
\text { implemented to } \\
\text { evaluate the } \\
\text { performance of } \\
\text { WBAN MAC }\end{array}$ & $\begin{array}{c}\text { health } \\
\text { monitoring }\end{array}$ & CSMA/CA \\
\hline $\begin{array}{l}\text { Mohammad } \\
\text { Sadegh et al }\end{array}$ & $\begin{array}{l}\text { packet detection and } \\
\text { reception are studied and the } \\
\text { performance factors are } \\
\text { analyzed in this paper }\end{array}$ & $\begin{array}{l}\text { analytical model } \\
\text { and a brief cross } \\
\text { layer study has } \\
\text { been implemented } \\
\text { in this methodology }\end{array}$ & $\begin{array}{l}\text { wireless } \\
\text { networks }\end{array}$ & IR UWB PHY \\
\hline $\begin{array}{l}\text { Mohammed Fatehy } \\
\text { et al }\end{array}$ & $\begin{array}{l}\text { Direct Sequence-Ultra Wide } \\
\text { Band(DS-UWB)is combined } \\
\text { with slotted-Aloha random } \\
\text { access to improve the } \\
\text { performance and channel } \\
\text { utilization }\end{array}$ & $\begin{array}{l}\text { various access } \\
\text { phase lengths, } \\
\text { processing gains, } \\
\text { and fading and noisy } \\
\text { channel models has } \\
\text { been evaluated by } \\
\text { simulations }\end{array}$ & $\begin{array}{l}\text { low-power in- } \\
\text { body/on-body } \\
\text { nodes }\end{array}$ & $\begin{array}{l}\text { slotted Aloha } \\
\text { based, IR UWB }\end{array}$ \\
\hline Yan Zhang et al & $\begin{array}{l}\text { protocol, data and control } \\
\text { channels are split to support } \\
\text { collision-free high data rate } \\
\text { communication. Application- } \\
\text { specific control channels are } \\
\text { adopted to provide priority } \\
\text { guarantee to the life-critical } \\
\text { medical application }\end{array}$ & $\begin{array}{l}\text { Monte Carlo } \\
\text { simulations are } \\
\text { carried out for } \\
\text { performance } \\
\text { evaluation }\end{array}$ & $\begin{array}{c}\text { medical } \\
\text { applications }\end{array}$ & $\begin{array}{c}\text { priority } \\
\text { guaranteed MAC }\end{array}$ \\
\hline Hiroki Katsuta et al & $\begin{array}{l}\text { performance evaluation for } \\
\text { ultra wideband (UWB)-based } \\
\text { wireless body area networks } \\
\text { (WBANs) through } \\
\text { experiments by using a } \\
\text { prototype }\end{array}$ & $\begin{array}{l}\text { conducted with } \\
\text { mounting the } \\
\text { system devices to } \\
\text { body in anechoic } \\
\text { chamber }\end{array}$ & $\begin{array}{l}\text { wearable } \\
\text { sensors }\end{array}$ & UWB PHY \\
\hline
\end{tabular}

Table 1: Brief literature survey on WBAN 


\section{Future Trends of WBAN}

WBAN opens a portal into new opportunities for research and development. Implementation of effective techniques can help this research improve in the areas of realtime health monitoring and ambient living environments. The WBAN is developing in such a way that implantable devices are at the reach of our technology. Implantable networks using BAN will provide a breakthrough in the field of medicine and real time monitoring. Cross layer protocols combining the functions of layers such as MAC and PHY have been proposed in order to improve the efficiency of the network system. Not just in the medical field, WBAN can also be implemented in gaming applications to improve the realism in gaming, this has proved to be an efficient tool for the next generation of gaming. Virtual realism in gaming is in a budding state where motion sensors are implemented to give the player a real experience. Implementation of WBAN will prove to be more effective in this area. This network is an efficient candidate for wearable sensors that help training and rehabilitation facilities. A method to diagnose Parkinson's disease has been proposed, similarly brain monitoring and ambient health monitoring are some of the unexplored areas in this field of study. IEEE 802.15.6 provides a numerous platforms to work through which will be very effective and would have a greater novelty.

\section{Conclusion}

WBAN is a promising technology that will play a major role in facilitating effective health monitoring and revolutionizing healthcare systems. This technology also will be a major breakthrough in the field consumer electronics and entertainment and others. In this paper the idea behind IEEE 802.15.6 is highlighted. The MAC protocols and physical layers and their access mechanisms were well addressed in this paper. A brief literature survey defining the state of art and the methodologies used were summed up in this paper. Certain possible future trends were also discussed in this article. As a future work the problems and challenges in this protocol will be studied and an application oriented research will be done.

\section{References}

Abbasi, U. F., A. Awang, and N. H. Hamid. 2013. "Performance investigation of opportunistic routing using log-normal and IEEE 802.15.6 CM 3A path loss models in WBANs". Paper presented at IEEE Malaysia International Conference on Communications (MICC), at Kuala Lumpur, Malaysia. 26-28 November, 2013. Accessed February 10th, 2015. DOI: 10.1109/MICC.2013.6805848.

Byoung Hoon, Jung, R. U. Akbar, and Sung Dan Keun. 2012. "Throughput, energy consumption, and energy efficiency of IEEE 802.15.6 body area network (BAN) MAC protocol". Paper presented at IEEE 23rd International Symposium on Personal Indoor and Mobile Radio Communications (PIMRC), at Sydney, Australia. 9-12 September, 2012. Accessed February 10th, 2015. DOI: 10.1109/PIMRC.2012.6362852.

"Carrier recovery." In Wikipedia - The free Encyclopedia. Accessed February 10th, 2015. http://en.wikipedia.org/wiki/Carrier_recovery.

Cavallari, R., and C. Buratti. 2014. "On the performance of IEEE 802.15.6 CSMA/CA with priority for query-based traffic". Paper presented at European Conference on Networks and Communications (EuCNC), at Bologna, Italy. 23-26 June, 2014. Accessed February 10th, 2015. DOI: 10.1109/EuCNC.2014.6882673.

Chowdhury, M. S., K. Ashrafuzzaman, and Kwak Kyung Sup. 2014. "Saturation Throughput Analysis of IEEE 802.15.6 Slotted Aloha in Heterogeneous Conditions." IEEE Wireless 
Communications Letters no. 3 (3):257-260. Accessed February 10th, 2015. DOI: 10.1109/WCL.2014.021714.140008.

Cypher, D., N. Chevrollier, N. Montavont, and N. Golmie. 2006. "Prevailing over wires in healthcare environments: benefits and challenges." IEEE Communications Magazine no. 44 (4):56-63. Accessed February 10th, 2015. DOI: 10.1109/MCOM.2006.1632650.

Dotlic, I., and R. Kohno. 2011. "Preamble structure and synchronization for IEEE 802.15.6 Impulse-Radio Ultra-Wideband physical layer". Paper presented at 5th International Symposium on Medical Information \& Communication Technology (ISMICT), at Montreux, Switzerland. 27-30 March, 2011. Accessed February 10th, 2015. DOI: 10.1109/ISMICT.2011.5759803.

Fatehy, M., and R. Kohno. 2013. "Variable Spread Slotted Aloha Simulation Analysis over IEEE 802.15.6 Using IR-UWB for Wireless Body Area Networks". Paper presented at European Modelling Symposium (EMS), at Manchester, UK. 20-22 November, 2013. Accessed February 10th, 2015. DOI: 10.1109/EMS.2013.95.

IEEE. 1999. IEEE Standard for Safety Levels with Respect to Human Exposure to Radio Frequency Electromagnetic Fields, $3 \mathrm{kHz}$ to $300 \mathrm{GHz}$. Accessed February 10th, 2015. DOI: 10.1109/IEEESTD.2006.99501.

IEEE. 2010. IEEE P802.15.6/D01,Wireless Medium Access Control (MAC) and Physical Layer (PHY) Specifications for Wireless Personal Area Networks (WPANs) used in or around a body.

IEEE. 2013. "IEEE 802.15 Wireless Next Generation Standing Committee". Accessed February 10th, 2015. http://www.ieee802.org/15/pub/TG6.html.

Istepanian, R. S. H., E. Jovanov, and Y. T. Zhang. 2004. "Guest Editorial Introduction to the Special Section on M-Health: Beyond Seamless Mobility and Global Wireless Health-Care Connectivity." IEEE Transactions on Information Technology in Biomedicine no. 8 (4):405414. Accessed February 10th, 2015. DOI: 10.1109/TITB.2004.840019.

Kahsay, L. Z., T. Paso, and J. linatti. 2013. "Evaluation of IEEE 802.15.6 MAC user priorities with UWB PHY for medical applications". Paper presented at 7th International Symposium on Medical Information and Communication Technology (ISMICT), at Tokyo, Japan. 6-8 March, 2013. Accessed February 10th, 2015. DOI: 10.1109/ISMICT.2013.6521691.

Katsuta, H., Y. Takei, K. Takizawa, and T. Ikegami. 2012. "Experiments of ultra widebandbased wireless body area networks with multi-nodes attached to body". Paper presented at Medical Information and Communication Technology (ISMICT), 2012 6th International Symposium on, at La Jolla, California, United States. 25-29 March, 2012. Accessed February 10th, 2015. DOI: 10.1109/ISMICT.2012.6203027.

Kyung Sup, Kwak, S. Ullah, and N. Ullah. 2010. "An overview of IEEE 802.15.6 standard". Paper presented at 3rd International Symposium on Applied Sciences in Biomedical and Communication Technologies (ISABEL), at Rome, Italy. 7-10 November, 2010. Accessed February 10th, 2015. DOI: 10.1109/ISABEL.2010.5702867.

Mohammadi, M. S., Zhang Qi, E. Dutkiewicz, and Huang Xiaojing. 2014. "Optimal Frame Length to Maximize Energy Efficiency in IEEE 802.15.6 UWB Body Area Networks." IEEE Wireless Communications Letters no. 3 (4):397-400. Accessed February 10th, 2015. DOI: 10.1109/LWC.2014.2321765.

$\mathrm{Ni}$, An, Wang Peikang, Yi Chenfu, and Li Ye. 2013. "Performance analysis of CSMA/CA based on the IEEE 802.15.6 MAC protocol". Paper presented at 15th IEEE International 
Conference on Communication Technology (ICCT), at Guilin, China. 17-19 November, 2013. Accessed February 10th, 2015. DOI: 10.1109/ICCT.2013.6820434.

Ortiz, A. M., N. Ababneh, N. Timmons, and J. Morrison. 2012. "Adaptive routing for multihop IEEE 802.15.6 Wireless Body Area Networks". Paper presented at 20th International Conference on Software, Telecommunications and Computer Networks (SoftCOM), at Split, Croatia. 11-13 September, 2012. Accessed February 10th, 2015. http://ieeexplore.ieee.org/xpl/articleDetails.jsp?arnumber=6347625.

Park, S., and S. Jayaraman. 2003. "Enhancing the quality of life through wearable technology." IEEE Engineering in Medicine and Biology Magazine no. 22 (3):41-48. Accessed February 10th, 2015. DOI: 10.1109/MEMB.2003.1213625.

Rashwand, S., J. Misic, and V. Misic. 2012. "MAC performance modeling of IEEE 802.15.6based WBANs over Rician-faded channels". Paper presented at IEEE International Conference on Communications (ICC), at Ottawa, Canada. 10-15 June, 2012. Accessed February 10th, 2015. DOI: 10.1109/ICC.2012.6364242.

Saleem, Shahnaz, Sana Ullah, and Kyung Sup Kwak. 2011. "A Study of IEEE 802.15.4 Security Framework for Wireless Body Area Networks." Sensors no. 11 (2):1383-1395. Accessed February 10th, 2015. DOI: 10.3390/s110201383.

Sarestoniemi, M., V. Niemela, M. Hamalainen, J. linatti, N. Keranen, T. Jamsa, J. Partala, T. Seppanen, and J. Reponen. 2014. "Receiver performance evaluation on IEEE 802.15.6 based WBAN for monitoring Parkinson's disease". Paper presented at 8th International Symposium on Medical Information and Communication Technology (ISMICT), at Firenze, Italy. 2-4 April, 2014. Accessed February 10th, 2015. DOI: 10.1109/ISMICT.2014.6825220.

Tachtatzis, C., F. Di Franco, D. C. Tracey, N. F. Timmons, and J. Morrison. 2010. "An energy analysis of IEEE 802.15.6 scheduled access modes". Paper presented at IEEE GLOBECOM Workshops (GC Wkshps), at Miami, Florida. 6-10 December, 2010. Accessed February 10th, 2015. DOI: 10.1109/GLOCOMW.2010.5700142.

Ullah, Sana, Henry Higgins, Bart Braem, Benoit Latre, Chris Blondia, Ingrid Moerman, Shahnaz Saleem, Ziaur Rahman, and KyungSup Kwak. 2012. "A Comprehensive Survey of Wireless Body Area Networks." Journal of Medical Systems no. 36 (3):1065-1094. Accessed February 10th, 2015. DOI: 10.1007/s10916-010-9571-3.

Van Dam, K., S. Pitchers, and M. Barnard. 2001. "Body area networks: Towards a wearable future". Paper presented at Proceedings of WWRF kick off meeting, at Munich, Germany. 6-7 March, 2001.

Yan, Zhang, and G. Dolmans. 2009. "A New Priority-Guaranteed MAC Protocol for Emerging Body Area Networks". Paper presented at ICWMC '09. Fifth International Conference on Wireless and Mobile Communications, at Cannes, La Bocca. 23-29 August, 2009. Accessed February 10th, 2015. DOI: 10.1109/ICWMC.2009.30. 